\title{
A novel organic solvent tolerant lipase from Bacillus sphaericus 205y: extracellular expression of a novel OST-lipase gene
}

\begin{abstract}
An organic solvent tolerant (OST) lipase gene from Bacillus sphaericus 205y was successfully expressed extracellularly. The expressed lipase was purified using two steps purification; ultrafiltration and hydrophobic interaction chromatography (HIC) to 8-fold purity and $32 \%$ recovery. The purified 205y lipase revealed homogeneity on denaturing gel electrophoresis and the molecular mass was at approximately $30 \mathrm{kDa}$. The optimum $\mathrm{pH}$ for the purified 205y lipase was 7.0ï 8.0 and its stability showed a broad range of $\mathrm{pH}$ value between $\mathrm{pH} 5.0$ to 13.0 at $37{ }^{\circ} \mathrm{C}$. The purified 205y lipase exhibited an optimum temperature of $55{ }^{\circ} \mathrm{C}$. The activity of the purified lipase was stimulated in the presence of $\mathrm{Ca} 2+$ and $\mathrm{Mg} 2+$. Ethylenediaminetetraacetic acid (EDTA) has no effect on its activity; however inhibition was observed with phenylmethane sulfonoyl fluoride (PMSF) a serine hydrolase inhibitor. Organic solvents such as dimethylsulfoxide (DMSO), methanol, p-xylene and ndecane enhanced the activity. Studies on the effect of oil showed that the lipase was most active in the presence of tricaprin (C10). The lipase exhibited 1,3 positional specificity.
\end{abstract}

Keyword: Bacteriocin release protein; Organic solvent tolerant lipase; Bacillus sphaericus 205y; Purification; Characterization 